\title{
Endovascular treatment of a triple paraanastomotic aneurysm after aortobiiliac reconstruction
}

\author{
Tratamento endovascular de triplo aneurisma para-anastomótico \\ após derivação aorto-biilíaca
}

\author{
Alexandre Campos Moraes Amato, ${ }^{1}$ Andrea Kahlberg, ${ }^{1}$ Luca Bertoglio, ${ }^{1}$ Germano Melissano, ${ }^{1}$ \\ Roberto Chiesa ${ }^{2}$
}

\begin{abstract}
We report a case of a 72-year-old patient considered unfit for open surgery, presenting with paraanastomotic aneurysms of all three anastomoses, 13 years after an open aortobiiliac reconstruction for abdominal aortic aneurysm. This patient was successfully treated with an endovascular approach using a left aortouniiliac endograft and a right iliac tubular endograft, followed by crossover femorofemoral bypass. This report illustrates the usefulness of a minimally invasive approach for solving this complication of aortic open surgery and discusses technical issues related to endovascular devices in this particular setting.
\end{abstract}

Keywords: Pseudoaneurysm, aortic and iliac surgery, endovascular repair, endovascular treatment, anastomosis, postoperative complications.

\section{Introduction}

Paraanastomotic aneurysm formation following prosthetic reconstruction of the infrarenal aorta may occur in 1 to $13.3 \%$ of patients, depending on the duration of follow-up in different series. ${ }^{1}$ Usually asymptomatic, it may present clinically as a pulsatile mass or less commonly complicated with rupture. ${ }^{2,3}$ Natural history includes frequently life-threatening complications, such as embolization, rupture, and erosion into adjacent organs. Conventional surgical treatment is associated with high mortality rates, ranging from 3 to $70 \%,{ }^{1,2,4-6}$ due to technical challenges related to dissection through previous scarred operative sites, poor quality of arterial wall and frequent comorbidities of these typically elderly patients. ${ }^{1,2,7}$ For these reasons endovascular stent

\section{Resumo}

Relatamos um caso de um paciente de 72 anos não considerado elegível para cirurgia aberta, apresentando aneurismas para-anastomóticos das três anastomoses, 13 anos após uma reconstrução aberta aorto-biilíaca para aneurisma aórtico abdominal. Este paciente foi tratado com sucesso através de abordagem endovascular usando uma endoprótese aorto-uniilíaca esquerda e uma endoprótese tubular ilíaca direita, seguida por derivação cruzada fêmoro-femoral. Este relato ilustra a utilidade de uma abordagem minimamente invasiva para o tratamento desta complicação da cirurgia aórtica aberta e discute questões técnicas relacionadas a dispositivos endovasculares neste contexto em especial.

Palavras-chave: Pseudo-aneurisma, cirurgia ilíaca e aórtica, reparo endovascular, tratamento endovascular, anastomose, complicações pós-operatórias.

grafting, owing to several potential benefits of its minimally invasive approach, represents an attractive therapeutic alternative to conventional surgery ${ }^{8}$ and has previously been shown to be feasible. ${ }^{2,6,9-12}$

We report the first case of a patient who developed a triple paraanastomotic aneurysm following aortobiiliac open reconstruction for abdominal aortic aneurysm and was treated with an endovascular approach.

\section{Case report}

A 72-year-old man was admitted at our service in March 2008 for a "triple" asymptomatic paraanastomotic abdominal aneurysm found during ultrasound screening. In 1995 he underwent aortobiiliac bypass graft

1. Chair of Vascular Surgery, Vita-Salute University, Scientific Institute H. San Raffaele, Milan, Italy.

2. Chief, Chair of Vascular Surgery, Vita-Salute University, Scientific Institute H. San Raffaele, Milan, Italy.

No conflicts of interest declared concerning the publication of this article.

Manuscript received May 20, 2008, accepted for publication Jun 19, 2008. 
$\left(16 \times 8 \mathrm{~mm}\right.$, Vascutek Terumo $\left.{ }^{\circledR}\right)$ due to an infrarenal aortoiliac aneurysm, and underwent regular follow-up up to 3 years after the first surgery, returning only 13 years later. He had a history of hypertension, two previous myocardial infarctions, with double coronary artery bypass graft surgery in 1990, bilateral carotid endarterectomy in 1993 and pacemaker-defibrillator implantation for ventricular arrhythmia in 2005.

No history of fever or symptoms of infection were reported. On admission blood exams showed no leukocytosis or any other inflammatory parameters. During preoperative stay he underwent diagnostic work-up, including Doppler echocardiography showing a left ventricular severe systolic dysfunction $($ ejection fraction $=$ $35 \%$ ), left atrial enlargement and mitral valve severe regurgitation. A computed tomography (CT) scan confirmed the presence of a perfused $4.7-\mathrm{cm}$ aneurysm of the infrarenal aorta at the proximal anastomosis level. Second and third leaks were displayed bilaterally at both distal iliac anastomoses, merging into a $10-\mathrm{cm}$ confluent perfused pseudoaneurysm (Figure 1).

Aortic infrarenal neck diameter and length were 22 and $16 \mathrm{~mm}$ respectively; distance from the caudal (right) renal artery to aortic graft bifurcation was $51 \mathrm{~mm}$; graft limb diameter was $12 \mathrm{~mm}$ bilaterally, left and right external iliac were 11 and $10 \mathrm{~mm}$ respectively. No periprosthetic fluid or air collection were found.

Due mainly to the patient's cardiac comorbidities, decision was to treat these lesions by placement of endovascular stent-grafts. Procedure was performed in the operating room and a portable digital $\mathrm{C}$-arm image intensifier was used. Both femoral arteries were exposed under locoregional anesthesia. A 26-mm aortouniiliac endograft (Zenith ${ }^{\circledR}$ Renu ${ }^{\mathrm{TM}}$ AAA Ancillary Graft; WilliamCook Europe Aps) with a 12-mm distal leg extension (Zenith Flex ${ }^{\circledR}$ Ipsilateral Iliac Leg; WilliamCook Europe Aps) was inserted through the left common femoral artery and deployed immediately below the renal arteries, excluding the proximal paraanastomotic aneurysm and covering the left iliac anastomotic leak, while keeping renal arteries flow. Then a tubular $16-\mathrm{mm}$ endograft (Gore Excluder ${ }^{\circledR}$ AAA Contralateral Leg; WL Gore and Assoc.) was inserted through the right common femoral artery and deployed covering the right iliac anastomotic leak (Figure 2).

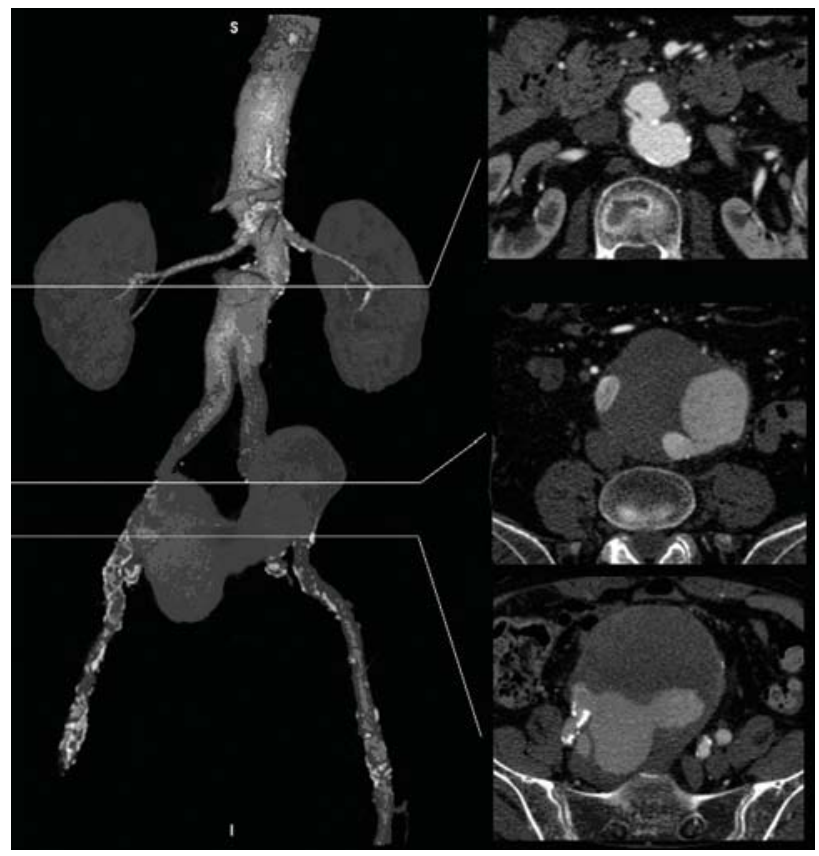

Figure 1 - A three-dimensional reconstruction of preoperative computed tomography scan showing the proximal and the distal paraanastomotic aneurysm, the latter originating from both the distal anastomoses of the previous aortobiiliac graft

The completion angiography showed correct positioning of the endografts, excluding all three paraanastomotic aneurysms, without evidence of endoleak. Following the endovascular procedure, a femorofemoral left-to-right bypass (InterGard ${ }^{\circledR} 6 \mathrm{~mm}$ ringed, InterVascular) was performed. Fluoroscopy performed at the end of the procedure showed the contrast media still lying in the distal pseudoaneurysm.

A follow-up CT scan demonstrated endograft and femorofemoral graft patency, right iliac artery occlusion, complete exclusion of proximal and distal paraanastomotic aneurysms, without evidence of endoleak (Figure 3). The postoperative period was uneventful and the patient was discharged home. He is alive and asymptomatic at 1 month follow-up.

\section{Discussion}

Open repair of paraanastomotic aortoiliac aneurysms requires laparotomy, dissection of the abdominal aorta in the scarred retroperitoneum and often suprarenal aortic clamping, entailing a high risk of adjacent 


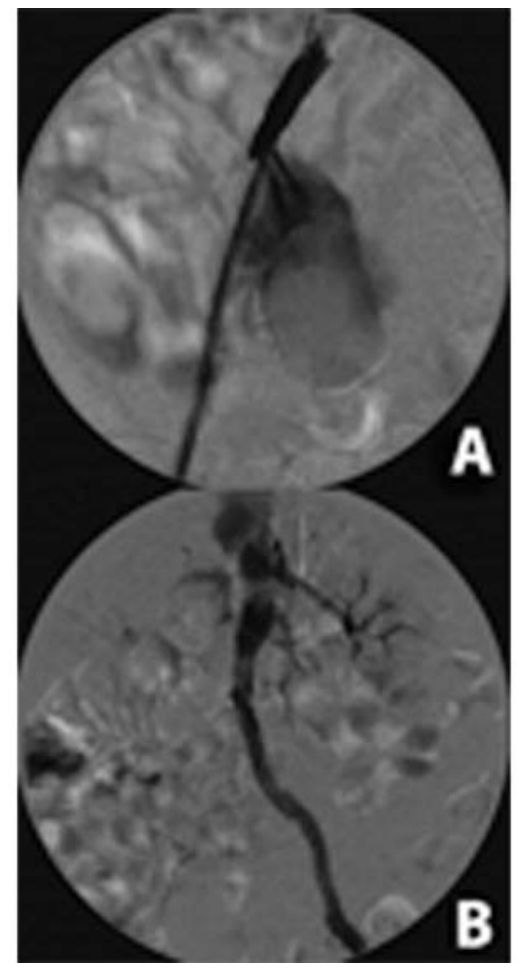

Figure 2 - Intraoperative digital subtraction angiography: A) distal right anastomotic leak; B) completion angiography, showing complete exclusion of the three paraanastomotic aneurysms without evidence of endoleak

organ lesions, conspicuous bleeding, renal and cardiac complications, with an overall increased mortality rate. ${ }^{13}$ Endovascular techniques carry a number of potential advantages, as they may avoid general anesthesia and aortic clamping, reduce operative blood loss and transfusion requirements, shorten hospital stay, finally limiting the overall physiological stress associated with conventional open surgery. Gawenda et al. ${ }^{2}$ showed that endovascular repair is safe and effective in this particular setting, reducing perioperative morbidity and complication rates, as stated in previous cases. ${ }^{10,11}$

Nevertheless, the "endovascular solution" in these cases has not yet been well defined and should be decided case by case, including different strategies of aneurysm exclusion and presenting with several issues and technical challenges. In the case presented, we opted for an aortouniiliac exclusion associated with a contralateral

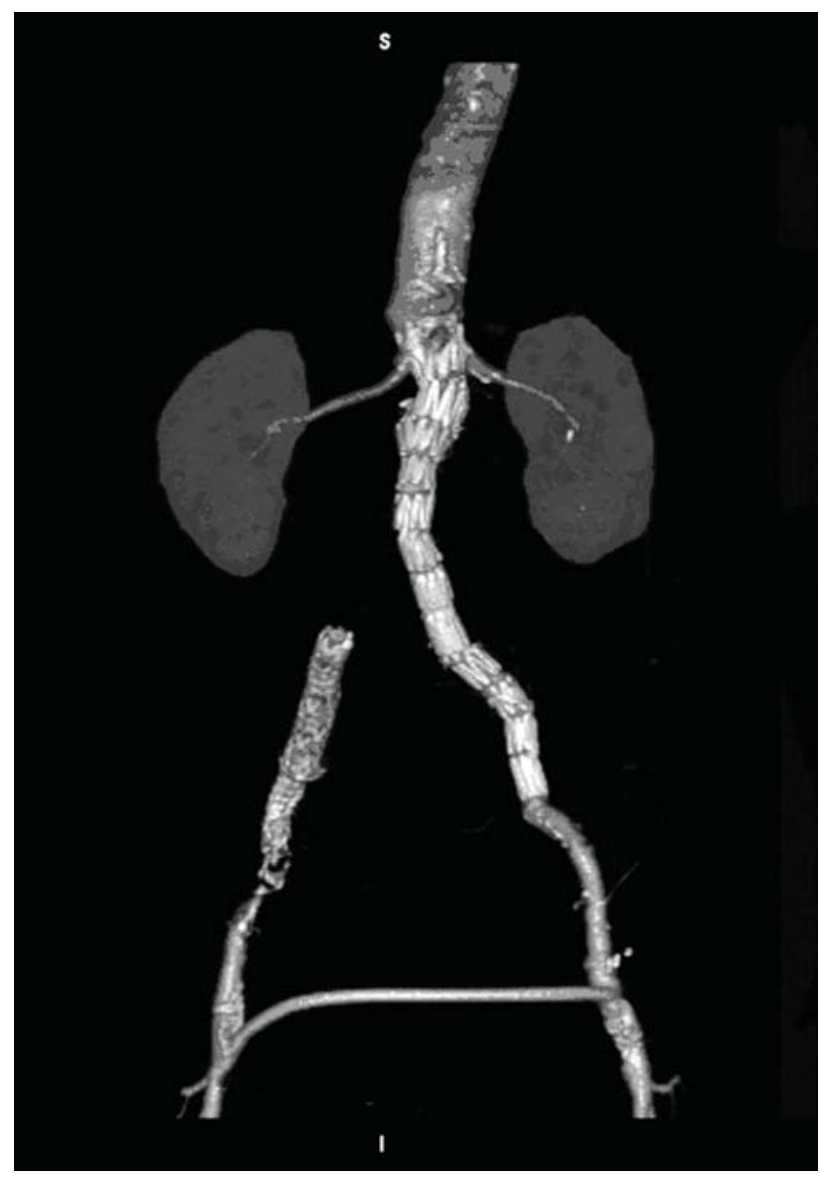

Figure 3 - A three-dimensional reconstruction of postoperative computed tomography scan showing left endografts and femorofemoral bypass graft patency, right iliac occlusion and complete exclusion of the three paraanastomotic aneurysms

iliac tubular endografting of the anastomosis site, followed by femorofemoral revascularization. This strategy is useful in case of aortic endografting after previous surgical implantation of a bifurcated Dacron graft, in which the "renal-to-bifurcation" aortic segment is too short to accommodate a typical main-body of a commercially-available bifurcated stent-graft. An aortouniiliac stent-graft was the alternative of choice. A specific "converter" device (Zenith ${ }^{\circledR}$ Renu ${ }^{\mathrm{TM}}$ Graft) with a short proximal large segment, followed by a long narrow iliac segment was used in order to fit this particular anatomy. In addition, the endograft is provided with a proximal bare stent that allows transrenal fixation, a very 
important feature when the infrarenal neck length is critical due to the presence of a proximal paraanastomotic aneurysm.

An alternative strategy to aortouniiliac stent grafting would have been to use only an aortic cuff to cover the proximal aneurysm, followed by two other iliac cuffs covering the distal aneurysms bilaterally. We find this option to be less durable, because the fixation of an endoprosthesis in a polyester graft depends on radial forces as well as on longitudinal columnar support, which is not provided with a single short cuff, entailing a higher risk of endoleak and/or migration. In this respect, Herwaarden et al. reported two cases of conversion to open repair, due to aneurysm growth in one case and to aneurysm rupture in another; in both patients a tubular stent graft was used to cover the paraanastomotic aneurysm. ${ }^{13}$

Another concern raised by the endovascular surgery is the need to cover the internal iliac arteries, with consequent risk of impotence, buttock claudication, bowel ischemia and even paralysis of the lower extremities. In this case, due to the complex origin of the distal huge pseudoaneurysm by both the iliac anastomosis, exclusion of the two internal iliac arteries was deemed necessary and fortunately was carried out successfully without complications. As there was no sign of endoleak after all stent graft deployment, and because a contrast media lying in the pseudoaneurysm was observed, the procedure was accomplished successfully.

In conclusion, this report confirms the feasibility of endovascular repair of paraanastomotic aneurysms, even in complex settings such as the case of triple aneurysm described herein.

\section{References}

1. Mulder EJ, van Bockel JH, Maas J, van den Akker PJ, Hermans J. Morbidity and mortality of reconstructive surgery of noninfected false aneurysms detected long after aortic prosthetic reconstruction. Arch Surg. 1998;133:45-9.
2. Gawenda M, Zaehringer M, Brunkwall J. Open versus endovascular repair of para-anastomotic aneurysms in patients who were morphological candidates for endovascular treatment. J Endovasc Ther. 2003;10:745-51.

3. Pagni S, Halene S, Kwass W, Khachane V. Ruptured aortic pseudo-aneurysm: a rare presentation as aortocaval fistula. J Cardiovasc Surg (Torino). 1997;38:165-8.

4. Treiman GS, Weaver FA, Cossman DV, et al. Anastomotic false aneurysms of the abdominal aorta and the iliac arteries. J Vasc Surg. 1988;8:268-73.

5. Gautier C, Borie H, Lagneau P. Aortic false aneurysms after prosthetic reconstruction of the infrarenal aorta. Ann Vasc Surg. 1992;6:413-7.

6. Nishibe T, Koizumi J, Kudo F, et al. Repair of false para-anastomotic aortic aneurysms using an endovascular stent graft technique in a patient with severe pulmonary disease: report of a case. Surg Today. 2001;31:1110-2.

7. Morrissey NJ, Yano OJ, Soundararajan K, et al. Endovascular repair of para-anastomotic aneurysms of the aorta and iliac arteries: preferred treatment for a complex problem. J Vasc Surg. 2001;34:503-12.

8. Brinster DR, McKee DM, Olsen DM, Berman SS, Rodriguez-Lopez JA. Endovascular treatment of a thoracic aortic pseudoaneurysm after previous open repair. Ann Thorac Surg. 2006;82:308-10.

9. Aun RASN, Lederman FTA, Waksman AA, Hilton. Tratamento endoluminal de aneurismas anastomóticos na aorta abdominal: relato de dois casos. J Vasc Bras. 2006;5:58-62.

10. Melissano G, Civilini E, Marrocco-Trischitta MM, Chiesa R. Resolution of an anastomotic aortic pseudoaneurysm 4 years after endovascular treatment. Tex Heart Inst J. 2004;31:330-2.

11. Melissano G, Di Mario C, Tshomba Y, et al. Endovascular treatment of a noninfected anastomotic juxtarenal aortic aneurysm. Tex Heart Inst J. 2000;27:408-11.

12. Lindblad B, Ivancev K, Chuter TA, Malina M, Brunkwall J, Risberg B. Endovascular exclusion of juxtarenal anastomotic pseudoaneurysm. Eur J Vasc Endovasc Surg. 1996;12:116-8.

13. van Herwaarden JA, Waasdorp EJ, Bendermacher BL, van den Berg JC, Teijink JA, Moll FL. Endovascular repair of paraanastomotic aneurysms after previous open aortic prosthetic reconstruction. Ann Vasc Surg. 2004;18:280-6.
Correspondence:
Dr. Germano Melissano, MD
Department of Vascular Surgery, IRCCS
H. San Raffaele
Via Olgettina, 60
20132 - Milan - Italy
Tel.: +39-02-2643-7146
Tel.: +39-02-2643-7148
E-mail: melissano.germano@hsr.it 